\title{
Effects of Hadi Project Implementation on the Resilience of Rural Settlements in Oraman, Sarvabad
}

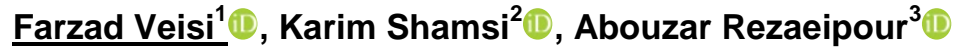

Date of submission: 7 Dec. 2018 Date of acceptance: 4 Mar. 2020

\begin{abstract}
INTRODUCTION: Resilience is recognized as the potential capacity of a system or community to adapt or resist change in order to maintain an appropriate level of performance and structure. Moreover, governments adopt a variety of strategies to mitigate the effects of natural disasters. In this regard, the rural Hadi project is an efficient method for rural physical management. The present study aimed to assess the effects of Hadi project implementation on rural resilience.

METHODS: The current study sought to investigate the effect of Hadi project implementation on the resilience of rural settlements in the villages of Oraman district. This descriptive-analytical study was conducted based on survey design. The statistical population of the present study consisted of the heads of households living in Oraman Takht district in which the Hadi project has been implemented at least 5 years ago. The participants were selected via the convenience sampling method. The data were analyzed using factor analysis, indexing, chi-square, Friedman test, and stepwise regression.

FINDINGS: Based on the results, the rural Hadi project had a positive significant effect on all the considered indicators $(\alpha=0.05)$. The effect size of this project on different dimensions of resilience was as follows: social resilience (257.45), economic resilience (208.95), institutional resilience (115.86), and environmental-physical resilience (196.69). Furthermore, a high correlation (0.993) was detected between the independent variable and the dependent variable. According to Friedman test, the greatest effect was exerted on the environmental-physical (3.23), institutional (3.00), economic (1.94), and social (1.51) dimensions, respectively.

CONCLUSION: As evidenced by the obtained results, the implementation of the rural Hadi project affected all rural resilience indicators. The implementation of this project exerted the most and least significant impact on the physical-environmental and social indicators, respectively. In fact, the implementation of this project is one of the effective methods for the enhancement of rural resilience indicators. Confirmatory factor analysis also verified the positive effect of Hadi project implementation on resilience indicators.
\end{abstract}

Original Article

Keywords: Oraman; Resilience; Rural Hadi Project; Rural Resilience; Sarvabad.

How to cite this article: Veisi F, Shamsi K, Rezaeipour A. Effects of Hadi Project Implementation on the Resilience of Rural Settlements in Oraman, Sarvabad. Sci J Rescue Relief 2020; 12(2): 152-163.

\section{Introduction}

$\mathrm{S}$ imilar to ecosystems, resilient societies must be able to withstand disruptions and adapt to change when required (1). Resilience is recognized as the potential capacity of a system, or community to adapt to or resist changes to achieve or maintain an appropriate level of performance and structure. In the absence of resilience, serious limitations would be imposed on the systems. Moreover, when resilience is impaired, the disruptions, such as disease, turbulence, or market fluctuations, that had already affected the systems exert enormous pressure on them bringing about significant

1-PhD, Geography Department, Payame Noor University, Tehran, Iran

2-MA, Geography and Rural Planning, Payame Noor University, Iran

3-PhD, Geography Department, Payame Noor University, Tehran, Iran

Correspondence to: Farzad Veisi, Email: Geoplan1392@gmail.com 
changes.

These fundamental alterations in the system bring about serious changes in the ecosystem and the well-being of people in different societies. It is obvious that resilience is one of the essential characteristics of resource management under conditions of uncertainty and change; therefore, resource management in such a manner has assumed more critical importance these days, compared to before (2). Based on the studies conducted over the last century, the weakness of local and regional planning has been one of the causes of developmental delay in Iran.

Rural development is deemed as one of the fundamental aspects of national development. The majority of the researchers emphasized that the prudent intervention of governments would result in the proper implementation of rural development programs with all its complexities (3). Rural Hadi project is one of the efforts of governments for the physical management of villages. This project is the most local rural development project in the country after the revolution (28).

Governments, on the other hand, adopt a variety of strategies to reduce the effects of natural disasters. Empowering the community to withstand risks, while development activities do not increase the community's vulnerability to risks, traditional risk reduction plans and programs have focused on the stability and resilience of physical systems (4). The main features of resilience entail: change thresholds, reorganization of resistance capacity, and coping or recovery from stressful events.

Natural ecosystems, as well as human and environmental systems, are regarded as the units of exposure (units of analysis) to resilience (2). The villages belonging to the Oraman district were the study area. These villages are exposed to various hazards due to their geographical location. Moreover, the implementation of every project carries its own problems due to the type of land in these regions. In recent years, the rural Hadi project has been implemented in this district; moreover, the pavements and other constructed buildings have become practically useless due to rural gas supply and wastewater piping operations.

The studies conducted on Hadi project and its effect on physical resilience raise the following questions: To what extent has the implementation of the rural Hadi project affected social resilience, economic resilience, institutional resilience, and physical-environmental resilience? The concept of resilience in social and environmental systems has been introduced since the 1980s (2). This concept was first proposed by Holling in ecological studies as a way to understand the nonlinear dynamics of ecological systems.

According to theorists, the majority of great civilizations of world history, including the Maya, the Norse, the Minoans, and the ancient siege empire, were eventually defeated by their enemies, as well as the adverse effects of floods, droughts, earthquakes, and tsunamis. From a new perspective, the aftermath of the December 2004 tsunami, which severely affected Asia, is unimaginable (the lives of more than 300,000 people were claimed in a single flood). Nonetheless, this mortality rate is not peculiar or record-breaking in the broader historical context since there have been other instances of natural disasters throughout the history of mankind (5).

Carpenter et al. (2001) provided a threedimensional definition for the resilience of socioecological systems: 1) the level of destruction and damage a system is able to absorb without going out of its normal state, 2)the ability of a system to reorganize itself in different situations, 3) the ability of the system to create and increase learning capacity and strengthen adaptation. In this approach, resilience is the opposite of vulnerability, which along with exposure and sensitivity, is known as one of the determinants of vulnerability (6).

The emergence of the word "disaster resilience" can be regarded as the advent of a new culture of disaster management. The UN World Conference on Disaster Reduction (WCDR) 2005 acknowledged that the concept of resilience has gradually become more widespread in both theoretical and empirical contexts in a wide range of areas discussed in disaster risk reduction. The vulnerability of rural communities is one of the limitations imposed on the development of these settlements, especially in areas that are constantly affected by disasters. Therefore, the resilience of rural communities can improve residents' living conditions and facilitates the development of these areas (7).

On the other hand, today, numerous villages in the country are facing different hazards, including desertification, deforestation, agricultural land-use 
changes, subsurface waterlogging, landslides, and earthquakes. Some environmental factors (e.g., climatic oscillations, earthquakes, and floods,) and human factors, as well as physical planning and other measures, are involved in the occurrence of the aforementioned conditions. Nevertheless, human factors exert increasing impacts on changing environmental conditions over time.

Moreover, this factor (human factor) has an exploitative attitude towards nature whether as the result of population growth (quantitative feature) or human-environment interaction that is affected by such factors as the level of technology, time, and the dominant pattern of planning (qualitative characteristics). In this regard, environmental resources are of paramount importance since they are the major livelihood resources of rural residents. One of the major environmental aspects of rural areas is physical development and planning. These programs form human-environment interactions through various construction and development plans (e.g., rural Hadi project and barren land development plan).

These changes, whether at the village, local, regional, or national levels, will take on a myriad of dimensions in the long run, and the resulting issues would present serious problems for the whole country. A resilient community is able to withstand the shocks and hazards to prevent disasters and catastrophes. Concurrently, these communities have the capacity to return to normal after the disaster, as well as the opportunity to change and adapt after disasters (11). Based on the concept of resilience, which should be related to all stages of disaster management, resilient societies need to have characteristics that cover all stages, including before, during, and after disasters.

Some studies have been conducted on the response of the resilience system to disasters by Joerin (2014) Bruneau et al. (2006), as well as Kim Hee and Shamai (2005). A high-resilient society has the capacity to accept these hazardinduced changes. However, a society which is fully resilient against disasters is an idealistic view, that is to say, no community can ever be completely safe from natural and human hazards (15). The role of local managers should not be forsaken in the provision of resilient settlements. Moreover, various forms of social capital perform a major role in the resilience of settlements. The indicators of social capital, including the components of trust, networks, and norms, are among the influential kinds of capital.

Putnam argues that participation in such communities as formal and informal networks of society is central to the concept of social capital (16). Moreover, economic, human, physical, and natural capital also affect the performance of resilient communities (Figure 1) (17).

Numerous studies have been conducted on resilience in recent years; nonetheless, they have mainly focused on urban areas (19) (22) (9) (8) (20), and there is a paucity of studies on rural resilience (23). Specifically, no research has been carried out on the effect of Hadi projects or development projects on rural resilience. The most important domestic and foreign studies on rural resilience will be discussed here. Wilson et al. (2018) in a study examined the resilience of the Chinese rural community in $\mathrm{Hu}$ Village, Sichuan Province, China.

The results demonstrated that in general, $\mathrm{Hu}$ village is relatively resilient in economic, social, and cultural aspects; nonetheless, the natural and political dimensions showed weak resilience (35). Ashkenazi et al. (2018) performed a study on the methods of operationalizing resilience in farms and rural regions in 14 cases. They concluded that based on empirical evidence, the strategies that may increase farmers' ability to survive in a difficult economic environment could undermine the resilience of a large area. Moreover, they added that the implementation of these strategies vary according to different spatial and temporal factors (34).

In another study conducted by Huang et al. (2018) on land use policy as a tool for rural resilience, they pointed to the mechanism of land reclamation for agricultural use in China. Based on findings, after policy implementation, rural resilience in Guangzhou, Chongqing, and Wuxi, as research settings, increased by $123 \%, 61 \%$, and $88 \%$, respectively. These changes in rural resilience have been mainly attributed to various modes of economic development in different regions, as well as various levels of land market development and government regulation.

In general, the implementation of WMRH 


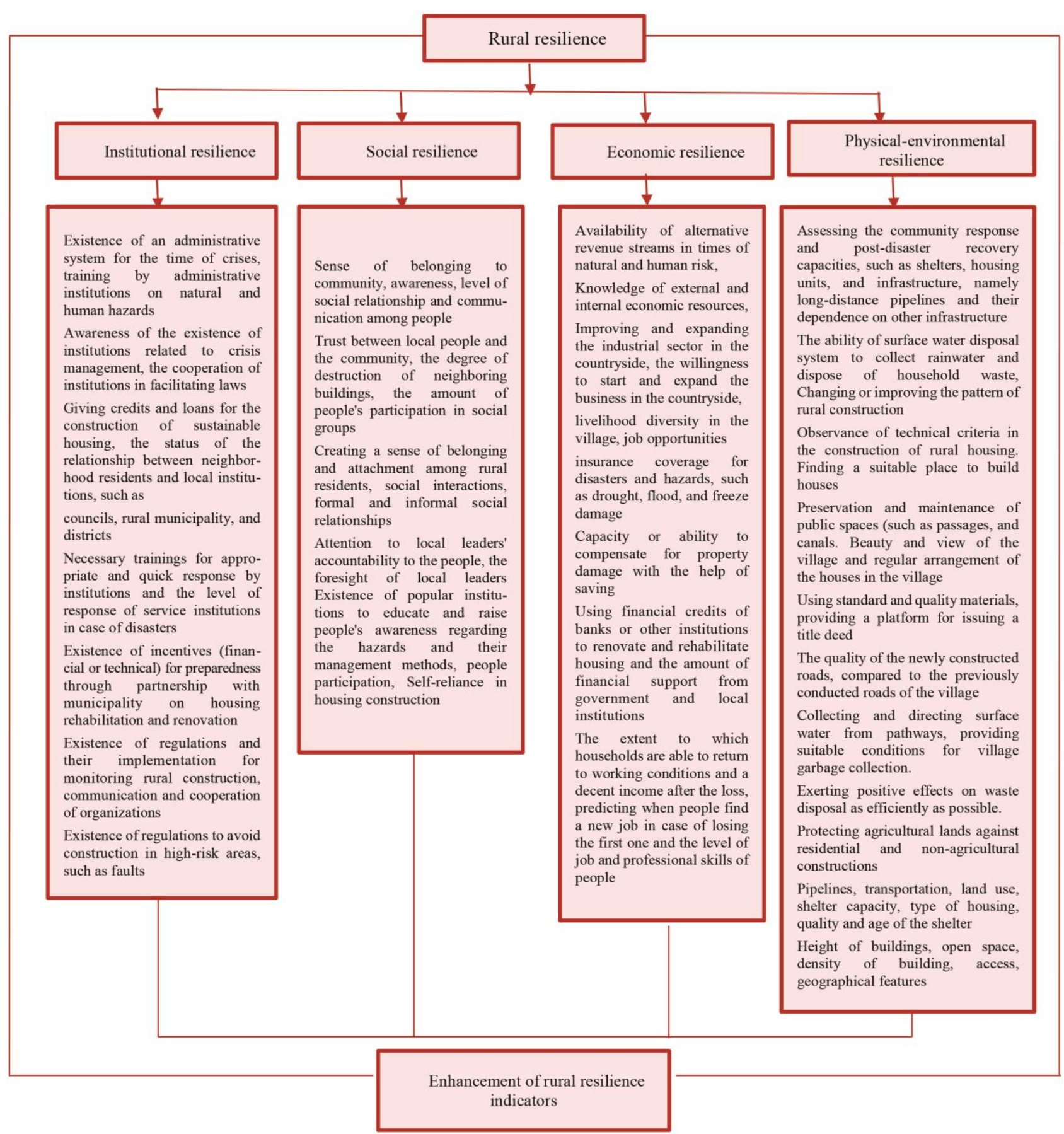

Figure 1. A conceptual model of research on how research indicators relate to the implementation of a rural Hadi project (3)

policy, along with a strong market and appropriate government regulation, boosted the rural resilience (37). Among the foreign similar studies, we can refer to a study performed by Rigg and Oven (2015) entitled "Building Liberal Resilience, a critical review from developing rural Asia". The mentioned article argues that "liberal resilience" has turned into a growth- development-resilience 'trap' in which economic growth has become an exact equivalent for development and resilience.

Moreover, there is a need for a critical judgment of the market mechanism that pursues resilience in contradictory and inconsistent ways (36). Robin Cox and Martin Hamlen (2013) described the development and field 
study of rural resilience indicators in an article entitled "Resilience against hazards in rural communities and rural resilience indicators". They introduced the indicators of rural resilience by highlighting the role of citizens in resilience planning and community-based approach to resilience (21).

Along the same lines, Munge (2012) examined the adaptive capacity and resilience of droughtprone farming families in southern New South Wales, Australia. This study identified a range of collective coping strategies used by households and pointed to farmers' reliance on social capital as a comparative resource (22). Several domestic studies have focused on rural resilience in recent years. Although no specific research exists on the resilience and implementation of rural Hadi project, some investigations have been carried out in the field of rural resilience, the most important of which are discussed below.

In a same vein, in their study, Boroumand et al. (2017) explained the resilience of rural areas against natural hazards with an emphasis on floods in Ghaen watershed. The results showed that the resilience of the studied villages is moderate; nonetheless, the resilience of the villages is different. Moreover, the villages of Ali Zangi and Fatehabad demonstrated the lowest resilience, despite being located in a high-risk area (31).

Anabestani et al. (2015) conducted a spatial analysis of the resilience level of rural settlements against environmental hazards in central Farouj. The results indicated that infrastructure and economic dimensions had the highest and least impact on rural resilience with the mean scores of 2.92 and 2.58, respectively. (32). In the same context, Taleshi et al. (2017) in an article developed and validated appropriate indicators for the assessment of rural resilience against the risk of drought in Hablehroud watershed.

The results of the mentioned study revealed that the most appropriate indicators included the increasing or decreasing trend in the natural resources of the village, the migration probability, access to various types of agricultural water resources, amount and level of agricultural land (ownership), insurance coverage and emergency services, agricultural development, livelihood diversity, household savings, and the future prospects of non-agricultural rural business activities (32).
In their study, Heidari-Sareban et al. (2016) investigated the role of livelihood diversity in the resilience of rural households living around the Lake Urmia against drought. The findings demonstrated that the adoption of a livelihood approach increased the resilience of households in conditions of drought in the Lake Urmia. (23). Nouri and Sepahvand (2016) in a study examined the resilience of rural settlements against natural hazards with an emphasis on earthquakes in Shirvan district, Borujerd. Based on the results of the referred study, the resilience of the studied villages against earthquake was lower than the average level, and the villages significantly differed in this regard. In addition, among the economic, social, infrastructural, and social capital dimensions of rural areas, social capital played the most significant role in the resilience of rural settlements (24).

In the same direction, Pourkoush et al. (2015) assessed the performance of rural management in terms of rural settlements resilience against natural disasters from the perspective of villagers in rural areas of Kermanshah. This study demonstrated that rural settlements are constantly exposed to threats and environmental hazards, especially natural hazards as other human settlements do (25). Based on Sadegh Lou and Sajasi Gheidari (2014), these days, resilience as one of the effective measures in the risk management process is a community-based approach to improve the preparedness of rural communities against disaster-induced instabilities and ensure the viability of rural settlements. The results of the stated study indicated that the enhancement of the viability of rural settlement resulted in increased community resilience (10).

Eftekhari et al. (2014) in another study showed that the adoption of livelihood diversity approach increased the resilience of households in drought conditions. This livelihood diversity is more pronounced in rural areas exposed to more severe drought (26). Badri et al. (2013) performed a study entitled "Role of local management in promoting spatial resilience against natural disasters with an emphasis on floods". The results of this study showed that the situation of the study community is appropriate in three principles of "organization and coordination", "management and protection of infrastructure", and "construction and land use laws ", and undesirable in the remaining seven principles (27). 


\section{Methods}

This descriptive-analytical study was conducted based on survey design. The data were collected through a questionnaire which measured and evaluated the most important indicators related to the effectiveness of the Hadi project. The statistical population of the present study consists of the heads of households living in Oraman Takht district in which the Hadi project has been implemented at least 5 years ago (the villages of the district include 14 villages, 3 of which are evacuated and 2 are under 20 households in which the Hadi project was not implemented; therefore, they were removed from the statistical community leaving 9 villages).

According to the 2011 census, these villages consisted of 2344 households $(\mathrm{N}=2344)$. The sample size was calculated at 330 people using Cochran's formula. In terms of number of villages, 4 villages out of 9 villages (i.e., $44 \%$ of the statistical population) were randomly selected as the study sample. The five-year interval between the implementation of the Hadi project and the present study was due to the tangibility of the effects of the project implementation for the villagers. For the purpose of the study, the heads of households in the study area were selected by random sampling method.

Data collection tool was a researcher-made questionnaire which consisted of 4 indicators and 30 items and is scored on a 5-point Likert-scale. Upon its design and development, the validity of this scale was approved by rural development and planning experts. Moreover, after executing 15 questionnaires, the reliability of this scale was obtained at 0.89 (as the mean of four indicators) using SPSS software (version 22). Data were analyzed using factor analysis, indexing, chisquare, Friedman test, and stepwise regression. Accordingly, to compare the mean of each dimension of resilience, the average was considered a basis for evaluating the projects. According to the direction of each group, scores above the average indicate more suitable conditions.

Oraman district belongs to Sarvabad in Kurdistan province covering an area of 217 square kilometers. This district is bordered by Dezli village from the north, Razab village from the east, Zherizhah Rural District from the southeast, Paveh in Kermanshah and Kamyaran from the west and southwest, respectively, and Iraq from the west. This region with a population of 9543 people and 2468 households covers two villages, namely Oraman Takht and Shalyar, as well as 1 city, 12 inhabited villages and 2 uninhabited villages (30).

\section{Findings}

Table 1 and Figure 1 display the information obtained from the questionnaire, the frequency of subjects based on gender and education.

Based on the descriptive results displayed in the above figure, out of 330 subjects, 188 (57\%) of cases were male and $142(43 \%)$ cases were female. Moreover, in terms of education level, out of 330 subjects, $107(32.4 \%)$ subjects had high school education, $143(43.3 \%)$ cases had a diploma, $80(42.2 \%)$ participants hold a bachelor's degree and higher. Therefore, according to the study sample, the subjects who had a diploma had the highest frequency.

Considering the significance level of variables $(0.01)$, it can be stated that the implementation of

Table 1. Variables, indicators, and items of research

\begin{tabular}{|c|c|c|c|}
\hline Variable & Dimensions & Indicator & Reliability \\
\hline $\begin{array}{l}\text { Rural } \\
\text { resilience }\end{array}$ & Social & $\begin{array}{l}\text { - Sense of belonging to community, awareness, level of social relationship } \\
\text { and communication among people } \\
\text { - Trust between local people and the community, the degree of destruction } \\
\text { of neighboring buildings, the amount of people's participation in social } \\
\text { groups } \\
\text { - Creating a sense of belonging and attachment among rural residents, } \\
\text { social interactions, formal and informal social relationships } \\
\text { - Attention to local leaders' accountability to the people, the foresight of } \\
\text { local leaders, } \\
\text { - Existence of social institutions to educate and raise people's awareness } \\
\text { regarding the hazards and their management method } \\
\text { - Peoples' awareness of the existence of institutions related to crisis } \\
\text { management, the status of the relationship between residents and local } \\
\text { institutions, such as council and rural municipality }\end{array}$ & 0.73 \\
\hline
\end{tabular}


- Existence of an administrative system for the time of crises, training by administrative institutions on natural and human hazards, the cooperation of institutions in facilitating laws,

Giving credits and loans for the construction of sustainable housing

- Necessary training for appropriate and quick response by institutions and the level of response of service institutions in case of disasters

Institutional - Existence of incentives (financial or technical) for preparedness through a partnership with the municipality on housing rehabilitation and renovation

- Existence of regulations and their implementation for monitoring rural construction, as well as communication and cooperation of organizations, - Communication and cooperation of organizations for risk management, the existence of regulations to avoid construction in high-risk areas, such as faults

- Availability of alternative revenue streams in times of natural and human risk

- Improving and expanding the industrial sector in the village, livelihood diversity, the willingness to start and expand the business in the countryside, the existence of job opportunities

- Insurance coverage for disasters and hazards, such as drought, flood, and freeze damage

Economic - Capacity or ability to compensate for property damage with the help of saving

- Using financial credits of banks or other institutions to renovate and rehabilitate housing and the amount of financial support from government and local institutions

- The extent to which households are able to return to working conditions and a decent income after the loss

- Predicting the time people may find a new job in case of losing the first one and the level of job and professional skills of people

- Assessing the community response and post-disaster recovery capacities, such as shelters, housing units and infrastructure, namely long-distance pipelines and their dependence on other infrastructure. The ability of surface water disposal system to collect rainwater and dispose of household waste

- Changing or improving the pattern of rural construction, Observance of technical criteria in the construction of rural housing

- Finding a suitable place to build houses, Preservation and maintenance of public spaces (such as pathways, and canals. Beauty and view of the village and regular arrangement of the houses in the village

Physical- - Using standard and quality materials, Beauty and view of the village and environmental regular arrangement of the houses in the village

- Providing a platform for issuing a title deed, the quality of the newly constructed roads, compared to the previously conducted roads of the village

- Collecting and directing surface water from pathways, providing suitable conditions for village garbage collection

- Protecting agricultural lands against residential and non-agricultural constructions

- Pipelines, transportation, land use, shelter capacity, type of housing, quality and age of the shelter, Height of buildings, open space, density of building, access, geographical features 


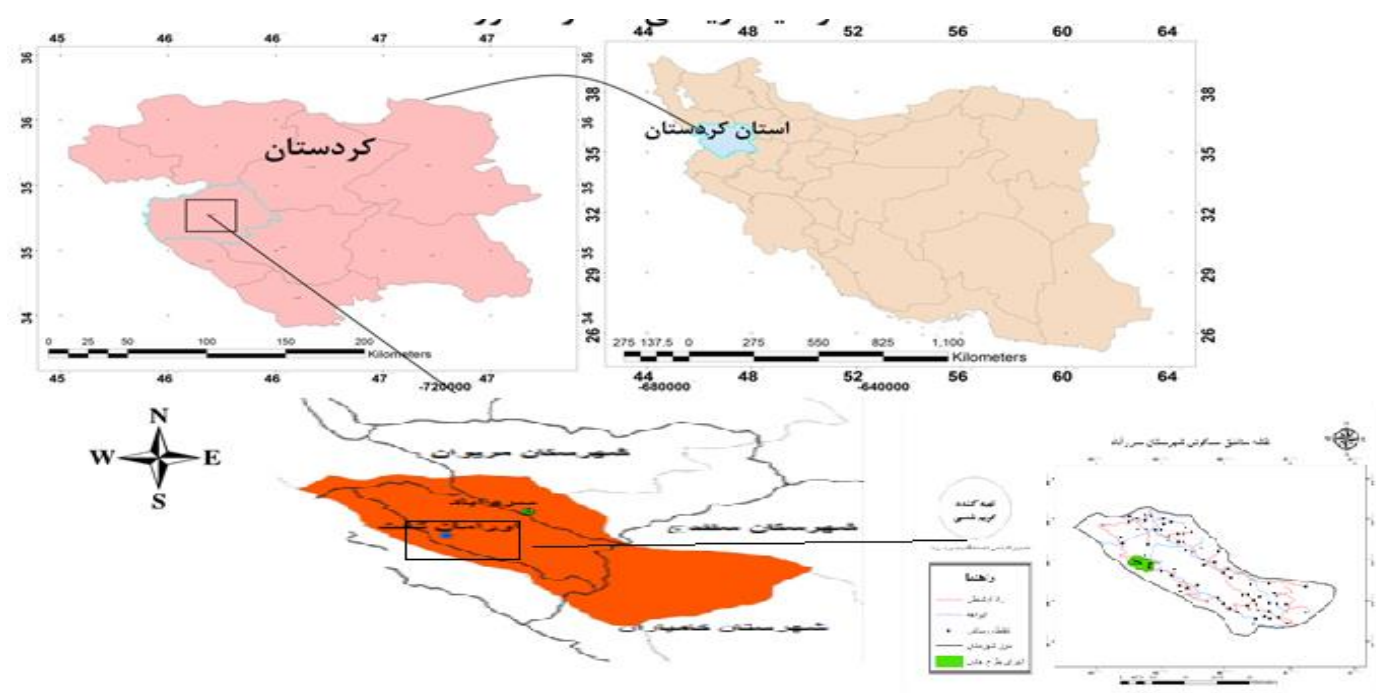

Mathematical position of the study area (Source: research findings)

the rural Hadi project had a significant effect on resilience indicators. The research hypothesis was confirmed since it was based on the effect of rural Hadi project on resilience indicators.

\section{Effect of rural Hadi project on resilience indicators}

As illustrated in Table 3, the rural Hadi project exerted the highest and lowest impacts on physical-environmental and social resilience indicators

The Friedman test was used to investigate the effect of the Hadi project on rural resilience. Based on the results presented in Table 4, it can be concluded that the implementation of the Hadi project had a positive effect on rural resilience indicators (Friedman value $=512.14, \mathrm{df}=3$, and $\mathrm{P}=$ 0.000)

Table 1. Frequency distribution of gender and education of subjects

\begin{tabular}{|c|c|c|c|c|c|}
\hline \multicolumn{2}{|r|}{ Variable } & Frequency & Percentage & Frequency $(\%)$ & Cumulative frequency \\
\hline \multirow{2}{*}{ Gender } & Male & 188 & 57 & $57 \%$ & 57 \\
\hline & Female & 142 & 43 & $43 \%$ & 100 \\
\hline \multirow{4}{*}{ Education } & High school & 107 & 32.4 & $32.4 \%$ & 32.4 \\
\hline & Diploma & 143 & 43.3 & $43.3 \%$ & 78.8 \\
\hline & Bachelor's degree and higher & 80 & 42.2 & $42.2 \%$ & 100 \\
\hline & Total & 330 & 100 & $100 \%$ & \\
\hline
\end{tabular}

Table 2. Result of one-sample t-test of the effect of rural Hadi project on resilience indicators

\begin{tabular}{|cccc|}
\hline Variable & t-value & Degree of freedom & Significance level \\
Social resilience & 6.22 & 329 & 0.000 \\
Economic resilience & 3.84 & 329 & 0.000 \\
Institutional resilience & 4.12 & 329 & 0.000 \\
Physical and environmental resilience & 6.97 & 329 & 0.000 \\
\hline
\end{tabular}

Table 3. Friedman test results concerning ranking four resilience indicators in terms of the affectability from rural Hadi project

\begin{tabular}{|c|c|}
\hline Items & Average rating \\
\hline Physical and environmental resilience & 3.22 \\
Institutional resilience & 3 \\
Economic resilience & 1.94 \\
Social resilience & 1.51 \\
\hline
\end{tabular}

\section{Regression Model Fitting}

As presented in Table 5, the correlation between the independent variables and the dependent variable is equal to 0.993 . The coefficient of determination is 0.98 . The independence of the residuals was inferred since the Durbin-Watson statistic was in the standard distance of 2.00-2.5. According to the mentioned 
Table 4. Results of Friedman test on the effect of Hadi project on rural resilience

\begin{tabular}{|ccccc|}
\hline Variable & $\mathbf{n}$ & Friedman value & Degree of freedom & Significance level \\
\hline Effect of rural Hadi project on resilience indicators & 330 & 512.14 & 3 & 0.000 \\
\hline
\end{tabular}

Table 5. Correlation between variables

\begin{tabular}{|cccc|c|}
\hline $\begin{array}{c}\text { Durbin- } \\
\text { Watson }\end{array}$ & $\begin{array}{c}\text { Standard } \\
\text { error }\end{array}$ & $\begin{array}{c}\text { Adjusted coefficient of } \\
\text { determination }\end{array}$ & $\begin{array}{c}\text { Coefficient of } \\
\text { determination }\end{array}$ & $\begin{array}{c}\text { Correlation } \\
\text { coefficient }\end{array}$ \\
\hline 2 & 1.85 & 0.98 & 0.98 & $0.993^{\mathrm{a}}$ \\
\hline
\end{tabular}

Independent variable: Hadi project

Dependent variable: Resilience dimensions (e.g., social, economic, environmental, and institutional)

indicators, the model has the necessary adequacy. In Table 6, the significance of the regression is calculated by F-test.

As demonstrated in Table 6, the obtained Fvalue (56683.51) is significant at the level of 0.000 . It is indicative of the significance of the regression, and the effectiveness of at least one of the independent variables in the prediction. The regression coefficients $\mathrm{B}$ and Beta illustrate this finding. The results of this study are depicted in Table 7.

In Table 7, the significance level of social, institutional, economic, and physical resilience is equal to 0.000 . Therefore, it can be concluded that the Hadi project affects all resilience variables since the significance level of all variables is less than significance level of 0.05 .

\section{Confirmatory factor analysis}

As presented in Table 8, the mediator variable was statistically significant based on the chisquare test $(\mathrm{df}=3 ; \mathrm{P}<0.000)$; nonetheless, this test is sensitive to large samples.

Other indicators, such as Good Fit Index (GFI), Comparative Fit Index (CFI), and Normalized Fit Index (NFI), are all less than the standard value of 0.90 . Moreover, the root mean square error of approximation (RMSEA) was more than the acceptable value (0.08) which indicates the fit of the model. Therefore, as evidenced by these findings, the implementation of the Hadi project has a positive effect on the

Table 6. ANOVA test statistics (analysis of variance) to examine the relationship between criterion variables and predictor variables

\begin{tabular}{|ccccccc|}
\hline & Model & Sum of squares & Degree of freedom & Average of squares & F-value & Significance level \\
\hline \multirow{4}{*}{1} & Regression & 78100.12 & 4 & 19525.03 & & 0.000 \\
& Residual & 1116.49 & 325 & 3.43 & 5683.51 & \\
\hline & Total & 79216.61 & 329 & & & \\
\hline
\end{tabular}

Table 7. Regression coefficients of Model 1

\begin{tabular}{|c|c|c|c|c|c|}
\hline Model & \multicolumn{2}{|c|}{ Non-standardized coefficient } & \multirow[t]{2}{*}{$\begin{array}{c}\text { Standardized coefficient } \\
\text { Beta }\end{array}$} & \multirow[t]{2}{*}{ t-value } & \multirow[t]{2}{*}{ Significance level } \\
\hline & B & Standard deviation & & & \\
\hline Constant value & 1.39 & 1.03 & & 1.35 & 0.178 \\
\hline Social & 1.03 & 0.11 & 0.21 & 8.76 & 0.000 \\
\hline Institutional & 0.89 & 0.06 & 0.20 & 14.61 & 0.000 \\
\hline Economic & 0.97 & 0.03 & 0.36 & 26.59 & 0.000 \\
\hline physical & 1.04 & 0.07 & 0.28 & 13.72 & 0.000 \\
\hline
\end{tabular}

Independent variable: Hadi project

Dependent variable: Resilience dimensions (e.g., social, economic, environmental, and institutional)

Table 8. Fitness indices of the studied model using AMOS software

\begin{tabular}{|c|c|c|c|c|c|c|c|c|}
\hline Model & $x^{2}$ & df & $\mathbf{P}$ & GFI & & CFI & NFI & RMSEA \\
\hline \multirow{3}{*}{ Hypothetical model } & \multirow{3}{*}{246.20} & \multirow{3}{*}{3} & \multirow{3}{*}{$\mathrm{P}<0.000$} & Original model & 0.741 & 0.587 & 0.586 & 0.627 \\
\hline & & & & Saturated model & 1 & 1 & 1 & 0.421 \\
\hline & & & & Independent model & 0.556 & 0.000 & 0.000 & 0.690 \\
\hline
\end{tabular}

160 Sci J Rescue Relief 2020; Volume 12; Issue 2 
resilience of rural settlements.

\section{Discussion and Conclusion}

Rural Hadi projects are one of the major development programs in the country and the most important rural development project. On the other hand, resilience, especially rural resilience, has become a prominent concept in risk management in recent years. The current study assessed the effect of implementing the Hadi project on the economic, social, institutional, and physical-environmental dimensions of rural resilience. The obtained results evidenced that the implementation of the Hadi project has affected all indicators of rural resilience.

Moreover, the most pronounced effect was exerted on the physical-environmental dimension, while the social dimension was the least affected indicator. In addition, the institutional and economic dimensions ranked second and third in terms of the affectability from the Hadi project. According to the obtained results concerning the items of the questionnaire, it can be stated that in the social dimension, such items as a sense of belonging to society, social relationships, and the participation of people in social groups can be influenced by the Hadi project.

Furthermore, the following items in the economic dimension are effective in economic resilience: job opportunities, insurance coverage for disasters, such as drought, floods, and freeze damage, the ability to compensate for property damage with the help of savings, the use of bank credits for the construction and renovation of resilient housing, and the amount of financial support from government and local institutions.

Moreover, in the institutional dimension, such indicators as self-reliance in housing construction, the cooperation of institutions in facilitating laws, giving credits and loans for the construction of sustainable housing, the status of the relationship between the residents and local institutions, such as councils and rural municipality, training for an appropriate response, and the preparedness of the organization and the response of service organizations are effective in the event of hazards. On a final note, in the physical-environmental dimension, the Hadi project can affect such indicators as providing suitable conditions for waste collection from the village, proper disposal of wastewater and household waste, protection of agricultural lands against residential and non- agricultural construction.

Based on the findings, it can be concluded that different indicators of rural resilience were not affected to the same degree by the Hadi project. Nonetheless, given the service description of the rural Hadi project and its implementation with a focus on the environment of the village, the most significant impact was related to physicalenvironmental resilience. On the other hand, since the issue of social resilience has been undermined in the service description and implementation of this project, rural social resilience was the least affected dimension.

Considering the large number of Hadi projects which are studied and implemented in the country, as well as the emergence of the concept of resilience and rural resilience for risk management, it seems that proper coordination and alignment can be established between these two issues. Moreover, apart from the physical management of villages, resilience indicators can be enhanced by devoting assiduous attention to resilience indicators, especially physicalenvironmental resilience in the service description of Hadi projects and during the implementation of projects.

In this regard case, the issue of resilience and its dimensions should be taken into account when the Housing Foundation and the Ministry of Interior cooperate in the development and implementation of the Hadi project. The physicalenvironmental dimension assumes more critical importance in this regard since a threat to the rural environment also endangers the social and economic dimensions of resilience.

Furthermore, the two aforementioned organizations should bear in mind that careful attention to the development and implementation of the Hadi projects concurrently improves the rural resilience indicators, especially in the physical-environmental dimension. Therefore, it is not necessary to re-prepare service descriptions and appoint a custodian for rural resilience. Based on the results, it seems that one of the methods for improving rural resilience indicators is the implementation of Hadi projects. These programs, apart from physical management at the village level as the primary goal of the project, can enhance resilience indicators.

Sustainable rural development, reduction of hazard losses, and risk management in rural areas have been long among the goals of 
researchers, planners, and governments. To increase the resilience of these settlements through the implementation of the Hadi project, the following suggestions are put forward:

1. Emphasis on the four indicators of resilience when developing and implementing Hadi projects to increase resilience in rural communities

2 . The promotion of local participation and exploiting the potential of traditional communities for the implementation and maintenance of Hadi projects (creation of local development institutions), the establishment of informal institutions, especially in the field of training and promoting crisis management, and enhancing resilience with the help of formal institutions and village councils

3. Considering the correlation between the implementation of the Hadi project and the promotion of rural resilience indicators, these indicators need to be taken into account in the development and implementation of the Hadi project. This can prevent further costs in crisis situations in the future.

4. The implementation of the Hadi project was less effective on social and economic indicators of rural resilience. Therefore, it is necessary to devote special attention to these two indicators when developing and implementing rural Hadi projects in order to simultaneously improve the four indicators of rural resilience.

\section{Acknowledgments}

The authors would like to express their gratitude to all those who contributed to the conduction of this research project.

\section{Conflict of Interests}

Authors have no conflict of interests.

\section{References}

1. Adger WN. Social and ecological resilience: are they related? Progr Hum Geography 2000; 24(3): 347-64.

2. Nelson V, Lamboll R, Arendse A. Climate change adaptation, adaptive capacity and development discussion paper. DSA-DFID Policy Forum; 2008.

3. Shammaei A, Ahmadabadi F, Ahmadabadi $\mathrm{H}$. Evaluation of the effects of conducting rural master of rural settlements (Case study: Neyshabour city). Rural Res Plan 2014; 6: 75-88. [In Persian].

4. Salehi E, Aghababaei MT, Sarmadi H, Farzad BM. Considering the environment resiliency by use of cause model. J Environ Stud 2011; 37(59): 99-112.
[In Persian].

5. Rokn al-Din Eftekhari AS, Badri AS, Sojasi Gheidari H. The theoretical foundations of physical planning in rural areas. $1^{\text {st }}$ ed. Tehran: Publication of the Islamic Revolutionary Housing Foundation; 2011. [In Persian].

6. Coppola DP. Introduction to international disaster management. Amsterdam, Netherlands: Elsevier; 2006.

7. Carpenter S, Walker B, Anderies JM, Abel N. From metaphor to measurement: resilience of what to what? Ecosystems 2001; 4(8): 765-81.

8. Rafieeian M, Rezaei M, Asgari A, Parhizkar A, Shayan S. Conceptual explanation of resilience and creation of its indicator in the community base disaster management. Spatial Plan 2012; 15(4): 1941. [In Persian].

9. Vana M, Soufi Neivani M. Assessment of resilience in urban waste tissue case study: serous district of Tehran. The first National Conference on the Key Issues in Civil Engineering, Architecture and Urbanism in Iran, Gorgan, Iran; 2016. [In Persian].

10. Vazifeshenas R, Shahin Baher I. The study of the system, principles and criteria for the resilience of the spatial and physical structure of cities. International Conference on Human, Architecture, Civil and Urban, Tabriz, Iran; 2015. [In Persian].

11. Sadeghloo T, Sojasi QH. Ranking of effective factors for farmer resilience increasing against of natural hazards (with emphasis on drought) study area: rural farmer in Ijroud county, Zanjan province. Geography Environ Hazards J 2014; 3(10): 129-53. [In Persian].

12. Davis I, Izadkhah YO. Building resilient urban communities. Open House Int 2006; 31(1): 11-21.

13. Joerin J, Shaw R, Takeuchi Y, Krishnamurthy R. The adoption of a climate disaster resilience index in Chennai, India. Disasters 2014; 38(3): 540-61.

14. Bruneau M, Chang SE, Eguchi RT, Lee GC, O'Rourke TD, Reinhorn AM, et al. A framework to quantitatively assess and enhance the seismic resilience of communities. Earthquake Spectra 2003; 19(4): 733-52.

15. Kimhi S, Shamai M. Community resilience and the impact of stress: adult response to Israel's withdrawal from Lebanon. J Community Psychol 2004; 32(4): 439-51.

16. Twigg J. Characteristics of a disaster-resilient community: a guidance note. London: Department for International Development (DFID); 2007.

17. Ostovar Izadkhah Y. Definitions and models of resilience in natural disasters. J Disaster Prev Manag Knowl 2012; 2(2): 145-53.

18. Nourbakhsh S. The rule of social, cultural and economic capitals of volunteers to success in Konkor. Soc Dev Welfare Plan 2011; 2(4): 93-134. [In Persian]. 
19. Shammaei A, Ahmadabadi F, Ahmadabadi H. Evaluation of the effects of conducting rural master of rural settlements (Case study: Neyshabour city). Rural Res Plan 2014; 6: 75-88. [In Persian].

20. Shaw D, Scully J, Hart T. The paradox of social resilience: How cognitive strategies and coping mechanisms attenuate and accentuate resilience. Global Environ Change 2014; 25: 194-203.

21. Sharifi A, Yamagata Y. Principles and criteria for assessing urban energy resilience: a literature review. Renewable Sustainable Energy Rev 2016; 60: 1654-77.

22. Rattien S. The role of the media in hazard mitigation and disaster management. Disasters 1990; 14(1): 36-45.

23. Moench MH. Adaptive capacity \& livelihood resilience in water scarce areas: research results from South Asia and implications for the Middle East. Boulder, Colorado: Earthscan; 2012.

24. Islam AK, Deb UK, Amin MA, Jahan N, Ahmed I, Tabassum S, et al. Vulnerability to climate change: adaptation strategies and layers of resiliencequantifying vulnerability to climate change in Bangladesh. Patancheru, Telangana: International Crops Research Institute for the Semi-Arid Tropics; 2013.

25. Heidari-Sareban V, Majnouni-Toutakhaneh A. The role of livelihood diversity on the resilience of rural households living around the Lake Urmia against drought. J Spatial Analysis Environ Hazarts 2017; 3(4): 49-70. [In Persian].

26. Noori SH, Sepahvand FA. Analysis of rural area resilience against earthquake; case study: Shirvan District (Borujerd County). J Rural Res 2016; 7(2): 272-85. [In Persian].

27. Poursamakoush JM, Lesboey MR, Entezari A, Zolfaghari A. Management performance in aligning rural settlements against natural disasters from the viewpoint of villagers. The Second International Conference on Sustainable Development, Solutions and Challenges Focusing on Agriculture, Natural Resources, Environment and Tourism, Tabriz, Iran; 2015. [In Persian].

28. Eftekhari AR, Mousavi SM, Poortaheri M, Asl MF. Analysis of the role of livelihood diversity to rural household resilience in drought condition: case study of the drought exposed areas of Isfahan province. Rural Res 2014; 5(3): 42-6. [In Persian].
29. Badri SA, Ramezanzadeh LM, Asgari A, Ghadiri MM, Salmani M. The role of local management in improving resilience to natural disasters with emphasis on floods case study: Cheshmeh Kileh basin in Tonekabon County and Sardabrud Basin in Kelardasht County. Emerag Manag 2013; 2(3): $37-$ 48. [In Persian].

30. Azimi R, Azizpour F, Ghayour HA. Evaluation of the physical effects of rural conducting projects. The First National Conference on Housing and Physical Development of the Village, Zahedan, Iran; 2011. [In Persian].

31. Statistics center of Iran results of population and housing census of Kurdistan Province. Tehran: Statistical Centre of Iran; 2011. [In Persian].

32. Characteristics of villages of Kurdistan Province. Sanandaj: Kurdistan Management and Planning Organization; 2011. [In Persian].

33. Mododi Arkhodi M, Boroumand R, Akbari E. Explaining the resilience of rural areas against natural hazards with emphasis on flood. J Natural Environ Hazards 2020; 9(23): 151-72. [In Persian].

34. Anabestani A, Javanshiri M, Mahmoudi H, Darban Astaneh MR. Spatial analysis of villagers' resilience against environmental hazards (a case study of central district of Faruj county). J Spatial Analysis Environ Hazarts 2018; 5(1): 17-38. [In Persian].

35. Taleshi M, Aliakbari E, Jafari M, Akhlaghi SJ. Developing and validation of appropriate indicators for assessing rural resilience to drought risk (case study: Hableroud Watershed Basin). Iran J Range Desert Res 2018; 24(4): 881-96. [In Persian].

36. Ashkenazy A, Chebach TC, Knickel K, Peter S, Horowitz B, Offenbach R. Operationalising resilience in farms and rural regions-findings from fourteen case studies. J Rural Stud 2018; 59: 211-21.

37. Wilson GA, $\mathrm{Hu} \mathrm{Z}$, Rahman S. Community resilience in rural China: the case of $\mathrm{Hu}$ Village, Sichuan Province. J Rural Stud 2018; 60: 130-40.

38. Rigg J, Oven K. Building liberal resilience? A critical review from developing rural Asia. Global Environ Change 2015; 32: 175-86.

39. Huang X, Li H, Zhang X, Zhang X. Land use policy as an instrument of rural resilience-The case of land withdrawal mechanism for rural homesteads in China. Ecolog Indicators 2018; 87: 47-55. 